Boise State University

ScholarWorks

Social Work Faculty Publications and Presentations

School of Social Work

$1-1-2011$

Hearing the Voices of Lesbian Women Having Children

Misty Wall

Boise State University 


\title{
Hearing the Voices of Lesbian Women Having Children
}

\author{
Misty Wall \\ Boise State University
}

\begin{abstract}
Whether single, or in the context of a lesbian relationship, lesbian women are choosing to become mothers, often through adoption. The path of lesbian women choosing motherhood is fraught with challenges and often disappointments (Martin, 1993, Oswald, 2002, Perrin, 2002, Stacey, 1996). In the United States, women are still very much socialized to want to be mothers and the desire to be a mother is not contradicted by sexual orientation (DiLapi, 1989; Dalton \& Bielby, 2000). However, lesbian women receive messages that they should not want to be mothers and that they cannot be adequate mothers (DiLapi. 1989; Pies, 1990). Women who self identify as lesbian must negotiate the norms and expectations of a heterocentric and homophobic culture. Thus, for lesbian women, choosing motherhood requires careful consideration and much planning (Dunne, 2000). Thus, one can assume that for lesbian women, the decision making journey, wherever it leads, is challenging and unique. Hearing the voices of lesbian women, as they make the decision to have, or not have, a child is the focus of this work.
\end{abstract}

\section{Theoretical Framework}

It is essential that there is an increase in our understanding of the complex process of decision making that lesbian women must navigate in order to come to the choice to have, or not have, children. There is a emerging collection of research that lends itself to validating the experiences of lesbian women raising children (Dunne, 2000, Dalton \& Bielby, 2000, \& Oswald, 2002), providing evidence to the fitness of lesbian women (and gay men) to raise children (Flaks, Ficher, Masterpasqua, \& Joseph, 1995; Falk, 1989, Green, Mandel, Hotvedt, Gray, \& Smith, 1986; Golombock, Spencer, \& Rutter, 1983, Harris \& Turner 1985, Huggins, 1989; Kirkpatrick, Smith \& Roy, 1981), and studies that present theoretical links to the adversities that correlate lesbian women living in oppressive social systems (Pies, 1985). Yet, little chance has been afforded to lesbian women to share, first-hand, the nuisances of the contextual process encountered during the path of deciding to have, or not have, children. Thus, the current text integrates feminist standpoint theory with a phenomenological approach to describe the lived experiences of lesbian women wrestling with reproductive choices.

\section{Phenomenological Approach}

Phenomenological research asserts that it is worthwhile to understand the lived experiences of individuals. To that end, the researcher utilizes first-hand narratives of experiences among like groups and incorporates the narrative of the lived experience in the company of the perspective of the lived experience (Padgett, 2008). According to Padgett (2008) analysis within phenomenological research is aimed at uncovered the "essence" of meaning from the lived experience of a group of similar persons (in this case lesbian women making reproductive decisions).

\section{Researcher contextual experience}

Standpoint theory asserts that life experiences shape our understanding of the world around us and that those concrete experiences are valid and useful positions within which to begin research (Swigonski, 1994). The following is a brief account of the personal experiences of the researchers that may have shaped the structure and analysis of the data. Attempts to "bracket" personal experiences were done through member checking (using multiple persons to check and recheck coding and themes), personal journaling, and discussion sessions among researchers and graduate assistants.

The lead author of this work is an adult woman, who self identifies as lesbian. At the time the data were gathered, and research study designed, she was partnered, without children, with no current plans to have children. At the genesis of the project she had plans to have children "someday". During data collection she became the mother of three children via foster care and adoption. The second author of this manuscript is an adult woman, who self identifies as heterosexual, and has given birth to two children. Both authors have given the social construction of "motherhood" considerable thought and had many conversations about the topic. Approaching the topic of reproductive decision making through our shared lens of motherhood and sexual orientation is supported and 
encouraged within the stance of feminist standpoint theory which asserts that observations and interpretations of the lives of marginalized groups only become truly visible when viewed through a lens with similar experiences (Collins, 1989). Swigonski (1994) addresses this topic as well by articulating simply that marginalized groups, such as lesbian women, mothers, and women who choose voluntary childlessness, experience a different reality because of the negative social response to such positions. While the researchers positions may create unique opportunities to understand and articulate the experience of these research participants, a phenomenological approach was used to ensure that our personal standpoints did not hinder accurate reflection and interpretations of responses via use of a graduate research assistant, who self identified as single, heterosexual, without children, to check our interpretations of data.

\section{Methodology}

\section{Data Collection and Sampling}

Purposive snowball sampling was used to generate respondents for the current study. Organizations were located via an Internet "Google" search using several variations of the search term "gay and lesbian organizations" which yielded about 22,000 sites returned. Of those 22,000 search results approximately 700 had a working website and about 200 had information to contact someone via email. Because the Internet was used, gay and lesbian organizations were located worldwide and invitations to participate were distributed without regard to location. The contact person listed on the websites was sent an invitation to complete an online questionnaire that included a link to the questionnaire (offered through surveymonkey). The questionnaire consisted of 104 questions including demographic questions, all quantitative, with the exception of three qualitative questions. The invitation for participation also included a statement requesting that the message and survey link be forwarded to anyone they thought would be interested. Because snowball sampling was utilized it is difficult to know the response rate that was generated from the original 200 invitations that were sent. A total of 478 women completed the questionnaire and 397 completed the qualitative portions analyzed for this paper and all responses were gathered within a twomonth period.

\section{Research Design and Data Analysis}

The focus of qualitative research is on providing rich, thick, descriptions of common experiences among analogous individuals (Padgett, 2008). Phenomenological researchers often craft one, or two, far-reaching questions, which will provide lush imagery of lived experiences (Moustakas, 1994). In keeping with the spirit of phenomenological research design, participants were asked one broad question, "what is the most difficult thing for a lesbian women considering parenthood?" and in keeping with standpoint theory a statement was included on the research invitation that briefly introduced the researchers personal experience with the topic. Three researchers independently read all responses and provided initial coding suggestions. Discussion between each researcher occurred and a coding template was created (horizontalization). Horizontalization is a process of coding data which includes highlighting significant statements or quotes that provide an initial insight into participants' meaning making surrounding a phenomena (Moustakas, 2004). Once significant statements were identified, the researchers worked to develop a textual description of participant's experiences. The textual descriptions were then used to develop structural imagery and themes, which broadens appreciation of the textual descriptions through weaving in the contextual pieces of the experience (Moustakas, 2004; Padgett, 2008). Because data were so voluminous, each response was cataloged into a series of coding matrices. The definitive matrix integrated five crucial themes.

\section{Findings}

The 479 women who responded to the survey, 396 entered responses to the qualitative question. Respondents hailed from all over the world and ranged in age from 20 to 69 , with a mean age of 39.35 years (SD $=9.710$ years). Just under half of the sample currently had, or were co-parenting children (42.6\%). The majority of participants were partnered (62.2\%). About $20 \%$ of women had been previously married to a man, and $14.2 \%$ had children from a previous heterosexual relationship. Just over half (58.9\%) planned to have children at some point in their life, while $31.6 \%$ did not ever plan to have children. Respondents were highly educated with about $34 \%$ having completed a college degree. Racially, the sample consisted of $82.3 \%$ Caucasian, 9.9\% African American, 4\% Asian/Pacific Islanders, 4.7\% Latino/Hispanic, 1.7\% Bi-racial, and .3\% Native American. 
Fundamentally, respondents were delighted to be talking about their reproductive decision making process. One woman responded via email,

"Thank you for asking these questions. Deciding not to have a child was the single biggest decision of my life. One that I devoted many years of my life to and while I have been judged by my decision to remain voluntarily childless, no one has asked about how I came to that conclusion, or how that may be best for me."

While the majority of women expressed appreciation for being able to articulate their experience, many woman reflected on the certainty of social pressure for women to make a decision to become a mother, and the implied message given to all women that choosing motherhood would fulfill gender expectations and bring meaning and purpose to their lives. This comment speaks to the contradictory messages women receive about motherhood and how those messages are especially bewildering to lesbian women who must develop a "double consciousness" (Swigonski, 1994) that includes an awareness of the reality of the larger, more powerful groups, while finding a place for their own experience as well. One participant explained,

"The most difficult thing about a lesbian planning a family is social pressure -- both for and against having a child. Social inculcation of "child" as the meaning of life."

Five central themes emerged during data analysis. Of crucial consequence to respondents during reproductive decision-making process were the logistics of starting a family, financial strain of adoption and/or pregnancy, loss or lack of social and familial support, obstructive laws and politics, and fear of societal intolerance. Figure 1.1 provides a graphic conceptual map of themes that emerged through analysis.

Figure 1.1 Conceptual Map of the Most Difficult Thing for a Lesbian Considering Parenthood



Adoption, foster care, insemination, oh my!

Many women reminisced about the difficulty choosing from the multiplicity of possible paths to parenthood. The decision to have a child through a one night stand, to raise a child born of an unknown donor, to risk losing custody to a known donor in order to give the child a chance to know his/her biological father, and even more choices await lesbians navigating the path to, or away from, parenthood. One women reflects on the lengthy journey to parenthood with humor,

"actually BECOMING a parent \{is the most difficult part\}, whether becoming pregnant, or adopting. It is very difficult. Been there, done that. Could write a book!"

The preponderance of the women included in the sample favored beginning a family via artificial insemination by an unknown donor (25\%) (Wall, 2007). The second most preferred mode of starting a family was adoption (16.5\%) (Wall, 2007). One woman articulates the complexity of choosing the manner with which to begin a family, 
"For us, it was deciding wether or not to have a known donor and have those family ties - both of which have pros and cons to varying degrees. We went with unknown donors to lessen the family tree confusion and any legal issues about parental rights."

Numerous women responded that the most difficult part is deciding where to acquire sperm and what the role of "father" should become,

"Figuring out the donor: friend vs. known donor through a sperm bank"

Another woman added,

"How the your family will deal with your decision to have children without the maternal father present. I mean what do you do on Father's Day?"

Still another woman reflects on the magnitude of allowing her children to sharing biological family ties and implications of race,

"Decide what method to use to become pregnant. In the case of an interracial partnership, and having more than one child - should my kids have the same "father" or should they look alike (i.e. black partner use white sperm, white partner use black sperm, or use the same sperm for both partners, or have one partner give birth and use the same sperm)"

\section{The price of parenting}

For many lesbian women, the path to parenthood is one paved with cash currency. Artificial insemination and invetero start at about $\$ 12,000$ and are only successful 5 - 30\% of the time (http://www.cdc.gov/ART/ART2006). For many women in this study, the financial costs were overwhelming. As one explained,

"The expense of the trying to conceive process. It usually doesn't happen on the first attempt and at $\$ 500$ $\$ 1000$ per month to inseminate as well as the emotional toll it takes on the couple; it is a very expensive process. If you have to have invitro it is sometimes over $\$ 100,000$ that insurance doesn't pay for."

Two women reflect angst about the costs associated with biologically conceiving a child;

"the cost of having a child. AI or IVF are very expensive...it would have been much much cheaper if I had just went out and had a one night stand!!"

Another woman echoes,

"Financial means to do what you want to do - the methods of having a child (other than just finding a man and having sex) are cost prohibitive for a lot of families."

Even when a lesbian woman, or lesbian couple, surmounts the mammoth expenditure of having a child, more money woes lie ahead as they attempt to win legal support for their relationship and family. As one woman explained,

"Even after the expense of artificial reproduction, you have to begin to deal with the expense of adoption."

Another woman adds,

"Navigating through the state system to make sure both parents rights are protected to the fullest extent, and the cost of both the proecess and second parent adoption."

Hardly any states have statutes that permit second parent adoptions (California, Colorado, Connecticut, Vermont), which is the only legal process that legally ties two parents of the same sex to the child or children (http://www.thetaskforce.org/downloads/reports/issue_maps/2nd_parent_adoption_5_07_color.pdf.) Thus, same sex 
couples, lesbian parents, and co-parents, often find themselves making time and money-consuming trips across the country in an attempt to locatate judges who are willing to allow their families the legal securities offered to heterosexual couples at no financial or emotional cost. Another woman elaborated,

"The financial costs associated with getting pregnant and then costs setting up the legal documents that are essential to protect your family. We had to pay lawyers to draw up everything from wills, trusts, joint conservatorship, Suit of Parent and Child Relationship, Adoption homestudy and are now trying to find a judge who will approve our second parent adoption."

And, as another woman explains the burden of meeting the financial demands of parenting which become more difficult without extended family support. One woman explains,

"The financial underpinnings that go with the legal state of marriage is the most important item. This is followed by the lack of support by family members which becomes more important the less money a couple has."

Fighting for legal equivalency

Families headed by lesbian women are devastated by the lack of legal recognition for their relationships. Legal marriage has been connected to more than 1,000 federal benefits including adoption, inheritance, and survivor benefits (General Accounting Office, 1997). One woman reflects on the impact of not having equal access to the rights of marriage,

"There is always the fact that the partner doesn't have the same rights as a father would in a herosexal relationship. So I struggled with the fact that as the co-parent I had no rights to the baby if my partner left me or passed away."

Another woman reflects,

"The lack of legal security involved in raising children most states for most people. I.e, the lack of twoparent adoption in many states, the threat of a break-up leading to a denial of parental rights, the fear of grandparents attemtping to take away the child, hassles with instituions such as schools or doctors, etc."

One woman recounts fear of being forced to be out at work as a parent in a same sex relationship, but having no legal protection in the workplace, left her feeling vulnerable. She reflects,

"financial and employment issues, forced acknowledgement at work without employment protection, reduced legal protection of family bonds"

\section{Searching for support}

Within the lesbian community the role of women as mothers has been fiercely debated. In the 1960's and 1970's lesbian feminists were urged to claim homosexuality as a deliberate and passionate choice as a means to denounce heterosexist and oppressive roles of women as wife and mother (Russo, 1976). While others, especially black feminists have asserted that it was through the role of mother that her true freedom and place was found (hooks, 1983). One woman reflected on the lack of support from within her lesbian community,

"Negative backlash from lesbians who don't see children as part of their world is often more prejudicial than heterosexuals views on our lifestyle choice."

A small body of qualitative research exists suggesting that often times lesbian women fear losing the support of their family of origin once plans to start a family are revealed (Touroni \& Coyle, 2002, Murphy, 1989, Chabot \& Ames, 2004). Another woman reflects on the role of support from her family, 
"family acceptance. Having the acceptance of one's family member is almost as vital as breathing, itself. Being strong in the decision to have a child with your partner of the same sex and carrying out that decision in the face of family disapproval, is difficult. I also think that societal and religious acceptance is difficult. In some instances, one has to change their entire lifestlye/habits in order to feel comfortable/accepted (ex. being raised Baptist, but having to attend a lgbt friendly Methodist church)."

\section{Living with homophobia}

Lesbian women live within a homophobic and heterosexist world every day. However, lesbian women experience this oppression in a different way as parents. Many women reported that the possibility of his or her child experiencing discrimination as a result of their mothers' sexual orientation is the most difficult challenge facing lesbians choosing motherhood. One woman wrote,

"the knowledge of the extreme prejudice that the child will face is the most difficult part . You can't even turn on the radio, the news, the president's speech, without hearing how your family is going to somehow contribute to the downfall of society. The last election was very hard on our children. They asked why the president and Christians hated us."

Another contemplates the seeming inevitability of her children experiencing discrimination and prejudice by stating,

"Accepting that discrimination is something that you are introducing into your child's life and that it will always be a part of your child's life."

Another ruminates on the encounters of her children,

"trying to make sure your children do not get hurt. Kids are so cruel today. Both my girls were teased when their friends learned of their "gay" mom."

Another reported that the most difficult thing about starting a family for a lesbian woman or couple is,

"The fact that we are raising our son in a culture that despises our family"

When negative views from society are internalized, the result is internalized homophobia (Shidlo, 1994, Sophie, 1997). One woman reports on her continued struggle with internalized homophobia,

"I struggle with accepting that it's okay for me to parent, even though I already do."

\section{Discussion}

Lesbian women receive conflicting messages from society regarding child rearing. Initially, all women are socialized to want to be mothers. However, once a woman begins to self-identify as a lesbian, she begins to sort through messages that as a lesbian she cannot and should not parent. Women in this study seemed to wrestle with the logistics of starting a family, financial strain of adoption and pregnancy, losing or lack of social and family support, unsupportive laws and politics, and fear of discrimination from society.

The many paths to parenthood available to lesbian women considering parenthood often leave women feeling overwhelmed and unsure where to start. Many women report feeling confused and even intimidated by the choices of how to start a family (Wall, 2007). Further adding to the difficulty of starting a family are often prohibitive medical and legal costs associated with pregnancy, childbirth, adoption, creating legal ties for the co-parent, and legal protections for the family (Wall, 2007).

Once the decision to have a child has been made, lesbian women begin searching for support within their families of origins, chosen families, and communities. This is often fraught with challenges as well. Many women reported losing support from their families of origin, not experiencing support as a co-parent, and some lost support from their gay and lesbian support groups. 
Finally, lesbian women report fear of discrimination for themselves and their children while deciding to parent, or not. Many women reported trepidation in coming out to adoption agencies, medical providers, and judges fearing potential denial of services, custody, or visitation. Moreover, many women reported experiencing these traumas again when they sought second parent adoption or other legal recognition of their child's co-parent.

\section{Limitations}

This research design was selected to encourage persons from around the world to respond, allow persons fearful of ramifications of disclosing their identity to participate, and increase the size of the sample, but it is not without limitations. One limitation is that there was only a single point for data collection, which may limit the depth of responses. Further, as data were collected via written responses to a single prompt it is feasible that misinterpretations were made during analysis. Finally, the use of a purposive snowball technique may have seriously impacted the type of respondents that participated.

\section{Implications}

According to the 2000 Census approximately 1:9 cohabitating couples are gay men or lesbians (http://www.census.gov/main/www/cen2000.html). Lesbians choosing motherhood are faced with creating their families in a society that does not support them. Political implications of research with lesbians and lesbian headed families highlight the importance of legitimizing same sex relationships and advocating for second-parent adoption privileges.

\section{Recognizing Same Sex Relationships}

Same-sex couples have sought to have their relationships legitimized within courts across the country by pursuing same-sex marriage, civil unions, and domestic partnerships and these concerns are clearly shared by the women who participated in this project as $89 \%$ of respondents said that they would marry their current partners if that was a legal option. Legal marriage is the only way in which lesbian couples can receive all the federal and social benefits of marriage that legitimize their relationships and families.

Practice implications resulting from growing knowledge about lesbians, lesbian headed families, and the decisionmaking process amongst lesbians considering parenthood include the need for practitioners to be aware of the various forms that families can take, and challenge assumptions that are based on traditional, two parent heterosexual family structures. Clinicians may also be aware of the potential impact that living in a heterosexist and homophobic world creates for these women and their families. Also, as lesbian headed families are becoming more vocal, practitioners may be called upon to help navigate that decision making process. The current research was done with the aim of understanding the process through which a lesbian woman navigates the plan to have, or not have, a child. The results of this research may guide clinicians in the development of evidenced based practices. 


\section{References}

Chabot, J.M., \& Ames, B.D. (2004). “It wasn't 'let's get pregnant and go do it':” decision-making in lesbian couples planning motherhood via donor insemination. Family Relations, 53(4), 348-356.

Dalton, S.E., \& Bielby, D.D. (2000). “That's our kind of constellation: lesbian mothers negotiate institutionalized understandings of gender within the family. Gender \& Society, (14)1, 36-61.

DiLapi, E.M. (1989). Lesbian women mothers and the motherhood hierarchy. In F.W. Bozett (Ed.)., Gay and lesbianity and the family (pp. $101-121$ ). Binghamton, NY: Harrington Press.

Dunne, G.A. (2000). Opting into motherhood: lesbian women blurring the boundaries and transforming the meaning of parenting and kinship.

Falk, P. (1989). Lesbian women mothers psychosocial assumptions in family law. American Psychologist, 44,941 $-947$.

Flaks, D., Ficher, I., Masterpasqua, F., \& Joseph, G. (1995). Lesbian women choosing motherhood: A comparative study of lesbian women and heterosexual parents and their children. Developmental Psychology, 31(1), 105-114.

General Accounting Office, B-27586014 (1997).

Golombok, S., Perry, B., Burston, A., Murray, C., Mooney-Somers, J., Stevens, M., \& Golding, J. (2003). Children with Lesbian women Parents: A community study. Developmental Psychology, 39, 20-33.

Green, R., Mandel, J.B., Hotvedt, M. E., Gray, J., \& Smith, L. (1986). Lesbian women mothers and their children: a comparison with solo parent heterosexual mothers and their children. Archives of Sexual Behaviors, $15,167-184$.

Golombock, S., Spencer, A., \& Rutter, M. (1983). Children in lesbian and single parent households: psychosexual and psychiatric appraisal. Journal of Child Psychology and Psychiatry, 24, 551-572.

Harris, M., \& Turner, P. (1985). Gay and lesbian parenting. Journal of Gay and lesbianity, 12, 101-113.

Kirkpatrick, M., Smith, C., \& Roy, R. (1981). Lesbian women mothers and their children: a comparative study. American Journal of Orthopsychiatry, 51, 545-551.

Oswald, R.F. (2002). Resilience within the family networks of lesbian women and gay men: intentionality and redefinition. Journal of Marriage and Family, 64, 374-383.

Martin, A. (1993). The lesbian and gay parenting handbook: creating and raising our families. New York, New York: Harper Collins.

Moustakas, C. (1994). Phenomenological research methods. Thousand Oaks, CA: Sage.

Murphy, B.C. (1989). Lesbian women couples and their parents: the effects of perceived parental attitudes on the couple. Journal of Counseling \& Development, 68, 46-51.

Padgett, D. K. (2008). Qualitative methods in social work research. (2nd ed). New York: Sage.

Pies, C. (1990). Lesbian women and the choice to parent. Marriage and Family

Review, 14, 137-154.

Perrin, E.C. (2002). Technical report: co parent or second-parent adoption by same-sex parents. Pediatrics, 109, 341-344. 
Russo, N.F. (1976). The motherhood mandate. Journal of Social Issues, 32(3),143-153.

Shidlo, A. (1994). Internalized homophobia: conceptual and empirical issues in measurement. In B. Greene \& G.M. Greene (Eds.), Lesbian women and gay psychology: theory, research, and clinical application (pp. 176205). Thousand Oaks, CA: Sage.

Sophie, J (1987). Internalized homophobia and lesbian identity. Journal of Gay and lesbianity, 14, 53-65.

Stacey, J. (1996). In the name of the family: rethinking family values in the postmodern age. Boston: Beacon Press.

Swigonski, M.E. (1994). The logic of feminist standpoint theory for social work research. Social Work, 39(4), 387394.

Touroni, E., \& Coyle, A. (2002). Decision-making in planned lesbian families: an interpretative phenomenological analysis. Journal of Community \& Applied Psychology, 12, 194-209.

Unknown. (2010). Retrieved from http://www.census.gov/main/www/cen2000.html.

Unknown.(2007).Retrieved from http://www.thetaskforce.org/downloads/reports/issue_maps/2nd_parent_adoption_5_07_color.pdf on June 5, 2008.

Wall, M.L. (2007). Reproductive decision making among lesbian women. Ph.D. dissertation. The University of Texas at Arlington, United States - Texas. Retrieved July 7, 2008 from Dissertations \& Theses: Full Text data base. (Publication No. AAT 3259604). 